Bull. Mater. Sci., Vol. 18, No. 5, September 1995, pp. 549-555. (C) Printed in India.

\title{
X-ray analysis of different starch granules
}

\author{
VASUDEVA SINGH*, R GOPALKRISHNE URS, \\ H SOMASHEKARAPPA, S Z ALI* and R SOMASHEKAR \\ Department of Studies in Physics, University of Mysore, Manasagangotri, Mysore 570006 , \\ India \\ * Grain Science and Technology, Central Food Technological Research Institute (CFTRI), \\ Mysore 570005, India
}

MS received 24 April 1995; revised 19 July 1995

\begin{abstract}
Crystal sizes and lattice distortion parameters for root, pulse and cereal starch granules have been determined using observed $\mathrm{X}$-ray diffraction reflections by Fourier method. Enthalpy for the formation of the lattice in root, pulse and cereal starches has been estimated and compared. It is found that the crystal size is normally high in root starch compared to pulse and cereal starches.
\end{abstract}

Keywords. X-ray analysis; starch granules.

\section{Introduction}

Crystalline nature of starches play a dominant role in determining swelling and enzymic behaviour of starches. These properties vary with acid treatment. Such studies are important in understanding the digestion aspects of these starches. It is well-known that starches in their native state are semi-crystalline and that they give three $\mathrm{X}$-ray diffraction forms namely, the A-type starch for cereal, B-type for tubers and roots and C-type starch for pulse starch (Sterling 1968; Wu and Sarko 1977; Sarko and Wu 1978). The size of the unit cell of starch has been reported by Rundle et al (1944), Kreger (1951) and Kainuma and French (1971).

The dimensions of crystalline of starch for (110) and (020) reflections using Scherrer method have been reported (Hizukuri and Nikumi 1957; Hizukuri et al 1964; Robin et al 1974). This method does not take into account the possible lattice distortions like paracrystalline disorder present in these starches. The inadequacies that exist in Scherrer's method have been pointed out by earlier investigators (Warren 1955, 1959; Mignot and Rondot 1975; Zocchi 1980; Nandi et al 1984).

Fourier analysis of the diffraction peaks virtually eliminates all these ambiguities associated with Scherrer method. With instrumental broadening correction as suggested by Stokes (1948), Warren and Averbach (1950) have shown that these corrected Fourier coefficients can be used to separate out the crystal size and lattice disorder parameters. Relatively a very few applications of this method to carboliydrate polymers has been applied since it requires at least two or more orders of reflections from the same set of lattice planes.

Recently Somashekar et al (1989) and Hall and Somashekar (1991) considered various aspects of multiple and single order methods and suggested a suitable single order method to obtain crystallite size and lattice distortion fairly accurately.

In this paper, we begin with a brief review of the theory of Warren and Averbach (1950) as applied to a single order method by Hall and Somashekar (1991). 


\section{Theory}

The intensity profile of the $\mathrm{X}$-ray reflection from a partially crystalline sample like starch granules is a function of distribution of crystal sizes and of lattice disorder. Warren (1959) has shown that the quantities like crystal size $(\langle D\rangle)$ and the lattice distortion $(g)$ are related through the Fourier coefficients $A(n)$ of the profile $I(s)$ by

$$
I(s)=\sum_{n=-\infty}^{\infty} A(n) \cos \left\{2 \pi n d\left(s-s_{0}\right)\right\} .
$$

Here, $s_{0}$ is the value of $s(=\sin (\theta) / \lambda)$ at the peak of the profile, $d$ the mean spacing of the lattice plane causing the reflection and $n$ the harmonic number.

Also, the Fourier coefficients can be factorized into size $A_{\mathrm{s}}(n)$ and disorder coefficients $A_{\mathrm{d}}(n)$,

$$
A(n)=A_{\mathrm{s}}(n) \cdot A_{\mathrm{d}}(n)
$$

and these are not normalized. The reasons for using non-normalized Fourier coefficients are truncation of the profile and error in the background estimation and these affect the low order Fourier coefficients of the intensity profile and this has been explained in detail by Somashekar et al (1989). Under these circumstances, to use higher order coefficients, various analytical forms for the distribution of crystallite sizes have been investigated by Hall and Somashekar (1991) who suggest that the asymmetric exponential function for the crystal size distribution gives fairly good results. Using this exponential function, Hall and Somashekar (1991) arrive at the following expression

$$
\begin{aligned}
& A_{\mathrm{s}}(n)=A(0)(1-n /\langle N\rangle) ; \quad n \leqslant p, \\
& A_{\mathrm{s}}(n)=A(0)[\exp \{-\alpha(n-p)\} / \alpha\langle N\rangle] ; \quad n \geqslant p .
\end{aligned}
$$

The crystal size is given by

$$
D=\langle N\rangle d_{h k l} \text {. }
$$

$A_{\mathrm{d}}(n)$ is the disorder coefficient for a paracrystal with separation of neighbouring lattice planes having a Gaussian distribution of standard deviation given by

$$
A_{\mathrm{d}}(n)=\exp \left(-2 \pi^{2} m^{2} n g^{2}\right)
$$

where $m$ is the order of reflection and $g$ the paracrystallinity of lattice distortion parameter. Using (1),(2), (3) and (5) along with the experimental intensity profile data, it is possible to obtain the crystal size and lattice distortion parameters.

\section{Experimental}

\subsection{Materials}

Maize and Tapioca starches were procured commercially from the market. Potato starch was a gift from Prof. Dr W Kempf of Federal Research Centre for Cereal and Potato processing, Detmold. Wheat, ragi and bengal gram starches were isolated at laboratory scale according to the method of Singh V and Ali S Z (unpublished work) and Ali and Kempf (1986). 


\subsection{Recording of $X$-ray diffraction pattern}

The X-ray diffraction patterns from the starch granules were recorded using a flat film with nickel filtered $\operatorname{CuK} \alpha$ radiation $(\lambda=1.540 \mathrm{~A})$. Unit cell parameters reported for potato and corn starches by El. Hinnawy et al (1982) and Sarko and Wu (1978) were used in refinement procedure using SIMPLEX multi-dimensional minimization programme to index all the observed reflections. The cell parameters are given in table 1.

\subsection{Calculation of crystal size and lattice distortion parameters}

The intensity profiles of a well defined reflection were obtained using Jarrel-Ash microdensitometer. The profiles of all the reflections used to obtain crystal size and lattice distortion were assumed to be symmetric and the half where the overlap with the neighbouring reflection is minimum was used to determine the cosine Fourier coefficients $A(n)$. The background level was taken as that at which intensity became uniform and this was subtracted from all the points. The scattering angle was transformed to $\sin (\theta) / \lambda$ and the Fourier coefficients were calculated from these intensity data after they were corrected for Lorentz and polarization factors and also for non-linearity of the film response.

As a check in the calculations, the profile was resynthesized and compared with the original data. The instrumental line broadening was corrected using the method due to

Table 1. Microstructural parameters obtained from X-ray reflections for various starches.

\begin{tabular}{|c|c|c|c|c|c|c|}
\hline Starch & $(h k l)$ & $d(\AA)$ & $\langle N\rangle$ & $D(\AA)$ & $g(\%)$ & $\alpha^{*}$ \\
\hline $\begin{array}{l}\text { Potato } \\
\text { (root) }\end{array}$ & $\begin{array}{l}(001) \\
(140) \\
(131) \\
(103) \\
(132)\end{array}$ & $\begin{array}{c}15 \cdot 7 \\
5 \cdot 72 \\
5 \cdot 2 \\
4 \cdot 5 \\
3 \cdot 7\end{array}$ & $\begin{array}{r}3.03 \\
7.78 \\
11.23 \\
12.55 \\
16.06\end{array}$ & $\begin{array}{l}47 \cdot 66 \\
44 \cdot 50 \\
58 \cdot 17 \\
56 \cdot 48 \\
59 \cdot 90\end{array}$ & $\begin{array}{l}0.5 \\
3.0 \\
2.0 \\
2.0 \\
2.0\end{array}$ & $\begin{array}{l}0.009 \\
0.093 \\
0.067 \\
0.071 \\
0.081\end{array}$ \\
\hline $\begin{array}{l}\text { Tapioca } \\
\text { (root) }\end{array}$ & $\begin{array}{l}(140) \\
(150) \\
(132)\end{array}$ & $\begin{array}{l}5 \cdot 1 \\
4 \cdot 4 \\
3 \cdot 8\end{array}$ & $\begin{array}{l}2.62 \\
5.69 \\
7.98\end{array}$ & $\begin{array}{l}13 \cdot 34 \\
24 \cdot 87 \\
30 \cdot 32\end{array}$ & $\begin{array}{l}1.0 \\
1.0 \\
1.0\end{array}$ & $\begin{array}{l}0.016 \\
0.024 \\
0.028\end{array}$ \\
\hline $\begin{array}{l}\text { Bengal gram } \\
\text { (cereal) }\end{array}$ & $\begin{array}{l}(140) \\
(103) \\
(132)\end{array}$ & $\begin{array}{l}5 \cdot 2 \\
4 \cdot 4 \\
3 \cdot 3\end{array}$ & $\begin{array}{l}5 \cdot 19 \\
6 \cdot 71 \\
9 \cdot 84\end{array}$ & $\begin{array}{l}26 \cdot 93 \\
29 \cdot 32 \\
32.87\end{array}$ & $\begin{array}{l}1.0 \\
1.5 \\
1.0\end{array}$ & $\begin{array}{l}0.023 \\
0.039 \\
0.031\end{array}$ \\
\hline $\begin{array}{l}\text { Ragi } \\
\text { (pulse) }\end{array}$ & $\begin{array}{l}(140) \\
(103) \\
(132)\end{array}$ & $\begin{array}{l}5 \cdot 2 \\
4 \cdot 5 \\
3 \cdot 4\end{array}$ & $\begin{array}{l}6.91 \\
8.80 \\
3.94\end{array}$ & $\begin{array}{l}35 \cdot 86 \\
39 \cdot 16 \\
13 \cdot 32\end{array}$ & $\begin{array}{l}1.5 \\
1.0 \\
1.5\end{array}$ & $\begin{array}{l}0.039 \\
0.030 \\
0.030\end{array}$ \\
\hline $\begin{array}{l}\text { Wheat } \\
\text { (pulse) }\end{array}$ & $\begin{array}{l}(131) \\
(150) \\
(132)\end{array}$ & $\begin{array}{l}5 \cdot 1 \\
4 \cdot 4 \\
3 \cdot 3\end{array}$ & $\begin{array}{l}3.76 \\
8.72 \\
6.89\end{array}$ & $\begin{array}{l}19 \cdot 09 \\
38.09 \\
23.01\end{array}$ & $\begin{array}{l}2.0 \\
0.5 \\
0.5\end{array}$ & $\begin{array}{l}0.039 \\
0.015 \\
0.013\end{array}$ \\
\hline Maize & $\begin{array}{l}(140) \\
(103) \\
(132)\end{array}$ & $\begin{array}{l}5 \cdot 2 \\
4 \cdot 4 \\
3 \cdot 4\end{array}$ & $\begin{array}{l}6.65 \\
3.74 \\
6.27\end{array}$ & $\begin{array}{l}34 \cdot 51 \\
16 \cdot 34 \\
21 \cdot 19\end{array}$ & $\begin{array}{l}1.5 \\
1.5 \\
1.5\end{array}$ & $\begin{array}{l}0.039 \\
0.029 \\
0.038\end{array}$ \\
\hline
\end{tabular}

Cell parameters:

Root starch: $a=18 \cdot 50 \AA ; b=18 \cdot 50 \AA ; c=10 \cdot 40 \AA ;$ alpha $=$ beta $=90 ;$ gamma $=120$

Cereal starch: $a=18.5 \AA ; b=18.50 \AA ; c=10.47 \AA ;$ alpha $=$ beta $=90 ;$ gamma $=120$

Pulse starch: $\mathrm{a}=11 \cdot 90 \AA ; \mathrm{b}=17 \cdot 70 \AA ; \mathrm{c}=10.52 \AA ; \mathrm{alpha}=$ beta $=$ gamma $=90$. 
Stokes (1948) by recording X-ray diffraction pattern for aluminium foil under the same condition as for starch granules.

\subsection{The refinement procedure}

The calculation of the intensity profile using (1), (2), (3) and (5) requires four parameters namely lattice distortion parameter $(g)$, crystal size $\left(\langle N\rangle\right.$ or $\left.\langle D\rangle=\langle N\rangle d_{k k l}\right)$, error in the background and a parameter defining the width of the exponential distribution function of column lengths. Initial values of $(g)$ and $\langle N\rangle$ were obtained using the method of Nandi et al (1984). Using these values in the above mentioned equations, the

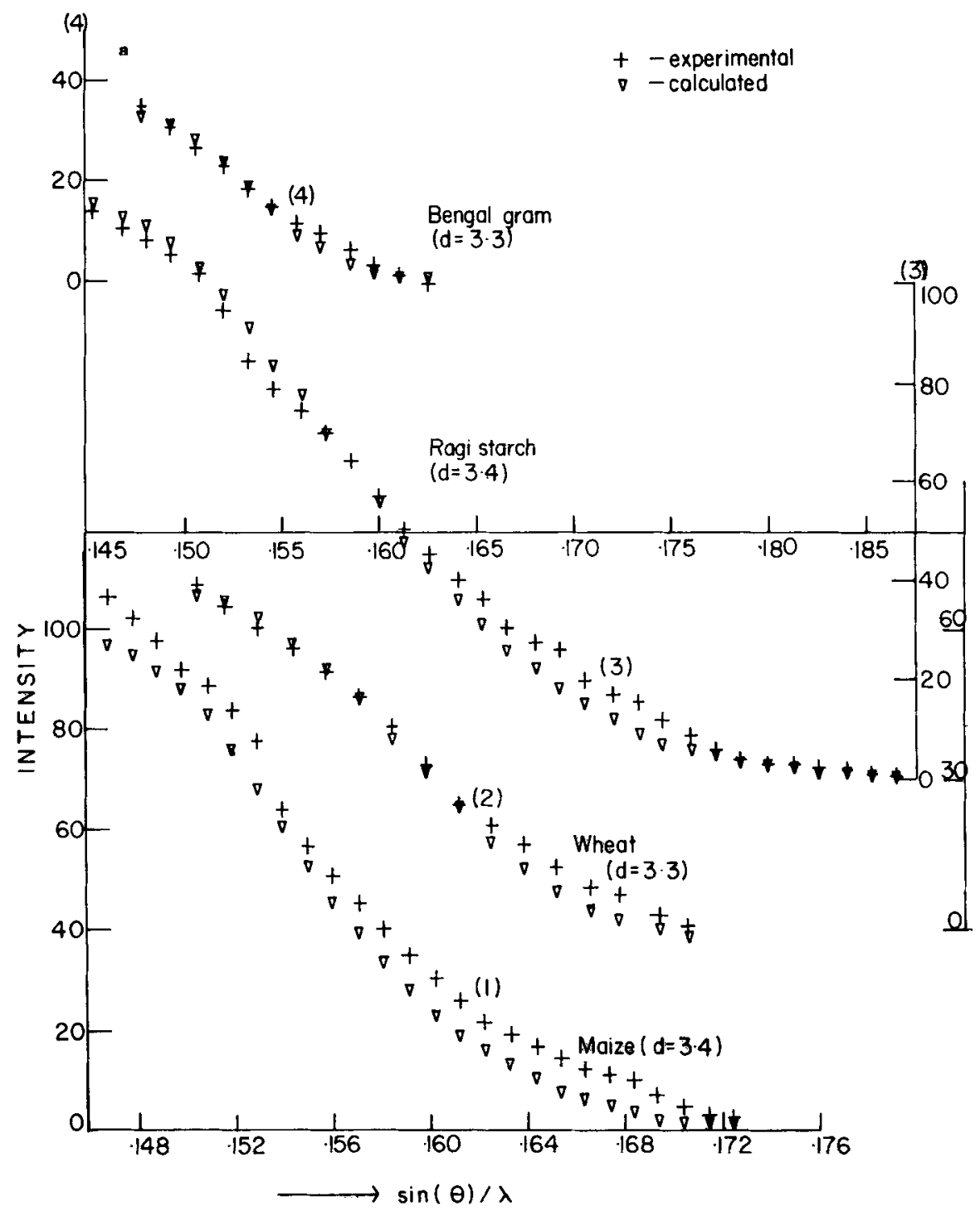

Figure 1. a. 


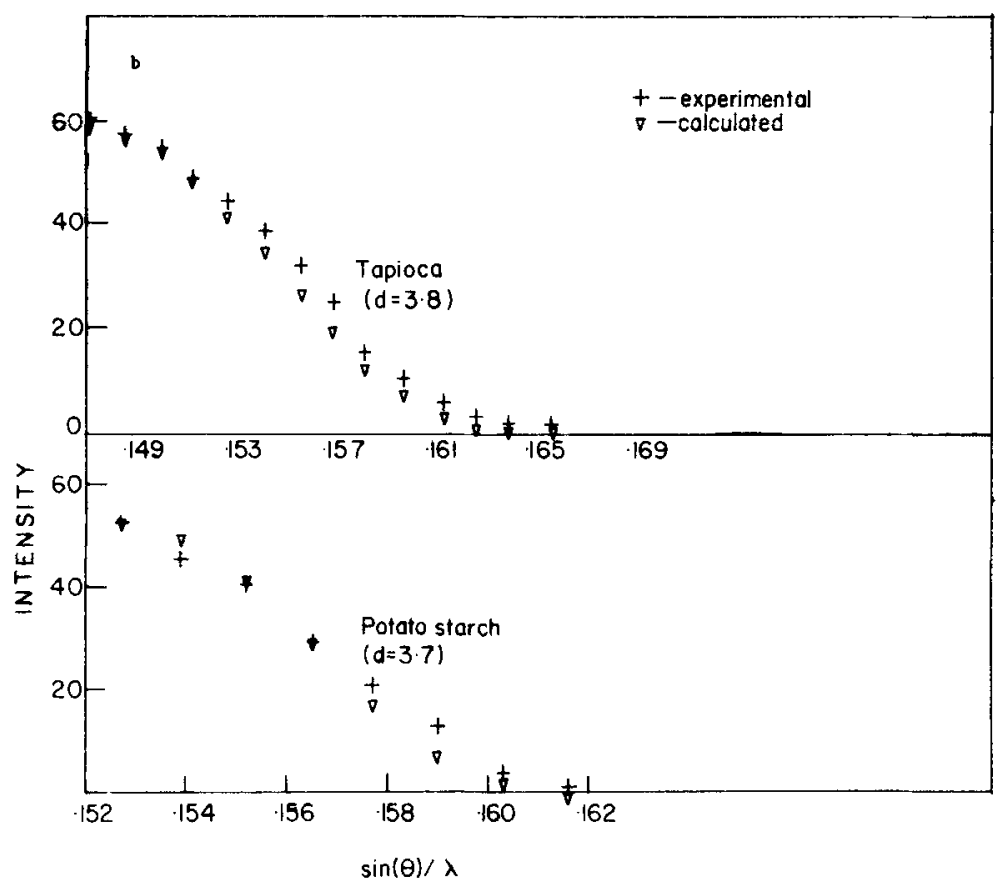

Figure 1. a. Calculated and experimental intensity profile of bengal gram, ragi, wheat and maize starches and $\mathbf{b}$. calculated and experimental intensity profile of Tapioca and potato starches.

corresponding values for the width of the distribution were obtained. These are only rough estimates, but refinement procedure must be sufficiently robust to start with such inaccurate values.

Here we compute

$$
\Delta^{2}=\left[I_{\text {cal }}-\left(I_{\text {exp }}+B G\right)\right]^{2} / \text { Number of points, }
$$

and this value of $\Delta$ was divided by half the maximum value of intensity so that it is expressed relative to the mean value of intensities and this function is minimized. For refinement, the multidimensional minimization algorithm of SIMPLEX method was used. Here we have used an asymmetric exponential function for the crystal size distribution as this gives better results. It was observed that the variation of $\Delta$ (defined in (6)) with $g$, the distortion parameter and all other parameters like $\langle N\rangle, p$ and $\alpha$ for exponential distribution function are almost constant and under these circumstances the average values of the parameters like $\langle N\rangle$ and $p$ were used to estimate average $g$ value. All the necessary computer programs were written in FTN language and were compiled and executed using Archimedes $310 \mathrm{M}$, Acorn, UK make.

\section{Results and discussion}

Table 1 gives the various parameters like the number of unit cells $\langle N\rangle$, width of the crystal size distribution $\alpha$, the smallest crystal unit $p$, lattice distortion parameter $g$ and zero order Fourier coefficients that are needed for recalculation of the intensity profile using equations mentioned earlier and figures $1 \mathrm{a}$ and $1 \mathrm{~b}$ show that there is good 
agreement between experimental intensity and the calculated intensity for a particular reflection observed in various starches.

It is observed that $g$, the distortion of the lattice, varies between 0.5 to $3.0 \%$ for root starch, 0.5 to $1.0 \%$ for cereal starch and 0.5 to $2.0 \%$ for pulse starch. This clearly indica tes that lattice distortion for root starch is considerably more than that for cereal and pulses.

Also from table 1 it is evident that the crystallite size in potato starch is large compared to tapioca, wheat, ragi and maize, i.e. the number of crystal lattice planes perpendicular to the observed X-ray reflection is more in potato starch than in other starch materials.

From these parameters, we can also estimate the minimum enthalpy, which defines the equilibrium state of microparacrystals in starch of various roots, cereals and pulses using the relation

$$
\alpha^{*}=\langle N\rangle^{1 / 2} g .
$$

This $\alpha^{*}$ value implies physically that the growth of paracrystals in a particular material is appreciably controlled by the level of $g$ in the net plane structure. This estimated minimum value of enthalpy is given in table 1 and we can conclude that the cereal and pulse starch which have smaller crystal size, consumes less energy in order to build up the crystal network compared to root starch. Note that the value of $\alpha^{*}$ lies between $0 \cdot 1$ and 0.2 for both man-made and natural fibres. These microparacrystal parameters are closely associated with the parallel arrangement of protein molecules comprising ala-ser-gly labile groups in the starch.

\section{Conclusions}

Crystal size and lattice distortion determined using single order method suggested in this paper are different for different types of starches. It is to be noted here that the lattice distortion which also contributes to the broadening of the X-ray reflection has been neglected by using Scherrer method. It has been emphasized in the paper that $g$, lattice distortion, is significant and the effect of treatment of starch with acid on these parameters must be studied by considering both crystal size and distortions of the lattice. The minimum enthalpy reported here determined the energy needed for the formation of crystal lattice network.

\section{References}

Ali S Z and Kempf P 1986 Starch 3883

El-Hinnawy S I, El-Saied H M, Fahmy A, El-Shirbeemy A E and El-sany K M 1982 Starch 3492

Hall I H and Somashekar R 1991 J. Appl. Cryst. 241051

Hindeleh A M and Hosemann R 1991 J. Mater. Sci. 265127

Hizukuri S and Nikumi Z 1957 Nature 180436

Hizukuri S, Kakudo M and Nikuni Z 1964 J. Agric. Chem. Soc. Jap. 38520

Kainuma K and French D 1971 Biopolymer 112241

Kreger D R 1951 Biophys. Acta 6406

Mignot J and Rondot D 1975 Acta Metallurgica 231321

Nandi R K, Kuo H R, Schlosberg M, Wisseler G, Cohen J B and Crist B J 1984 J. Appl. Cryst. 1722

Robin J P, Mercier C, Charbonnier R and Guilbot A 1974 Cereal Chem. 51389

Rundle R E, Daasch L and French D 1944 J. Chem. Soc. 66130 
Sarko A and Wu H-Ch 1978 Starch 3073

Singh V and Ali S Z 1987 Starch 39402

Somashekar R, Hall I H and Carr P D 1989 J. Appl. Cryst. 22363

Sterling C 1968 in Starch and its derivatives (ed.) J A Redley (London: Chapman and Hall) p. 159

Stokes A R 1948 Proc. Phys. Soc. London 61382

Warren B E 1955 Acta Crystallogr. 8483

Warren B E 1959 Prog. Metal. Phys. 8147

Warren B E and Averbach B L 1950 J. Appl. Phys. 21595

Wu H-Ch and Sarko A 1977 Carbohyd. Res. 54 C3

Zocchi M 1980 Acta Crystallogr. A36 164 